\title{
n-Alkanes, PAHs and surfactants in the sea surface microlayer and sea water samples of the Gerlache Inlet sea (Antarctica)
}

\author{
A.M. Stortini ${ }^{\text {a }}$, T. Martellini ${ }^{\text {b }}$, M. Del Bubba ${ }^{\text {b }}$, L. Lepri ${ }^{\text {b }}$, G. Capodaglio ${ }^{\text {c,a }}$, A. Cincinelli ${ }^{\text {b,* }}$ \\ a Institute for the Dynamics of Environmental Processes (CNR-IDPA), Calle Larga Santa Marta 2137, I30123-Venice, Italy \\ ${ }^{\mathrm{b}}$ Department of Chemistry, University of Florence, Via della Lastruccia 3, 50019, Sesto Fiorentino, Florence, Italy \\ ' Department of Environmental Sciences, University Ca' Foscari of Venice, Calle Larga Santa Marta 2137, I30123-Venice, Italy
}

\section{A R T I C L E I N F O}

\section{Article history:}

Received 3 May 2007

Received in revised form 10 November 2008

Accepted 16 November 2008

Available online 27 November 2008

\section{Keywords:}

Hydrocarbons

Antarctica

Sea-surface microlayer

Subsurface

Enrichment

\begin{abstract}
A B S T R A C T
Sea surface microlayer (SML) and sea water samples (SSW) collected in the Gerlache Inlet Sea (Antarctica) were analysed for n-alkanes and polycyclic aromatic hydrocarbons (PAHs). The SML is a potential enrichment site of hydrophobic organic compounds compared to the underlying water column. Total concentration ranges of n-alkanes and PAHs (dissolved and particulate) in subsurface water ( $-0.5 \mathrm{~m}$ depth) were 272 $553 \mathrm{ng} \mathrm{l}^{-1}$ (mean: $448 \mathrm{ng} \mathrm{l}^{-1}$ ) and 5.27-9.43 $\mathrm{ng} \mathrm{l}^{-1}$ (mean: $7.06 \mathrm{ng} \mathrm{l}^{-1}$ ), respectively. In the SML, the concentration ranges of n-alkanes and PAHs were 353-968 $\mathrm{ng} \mathrm{l}^{-1}$ (mean: $611 \mathrm{ng} \mathrm{l}^{-1}$ ) and 7.32-23.94 $\mathrm{ng} \mathrm{l}^{-1}$ (mean: $13.22 \mathrm{ng} \mathrm{l}^{-1}$ ), respectively. To evaluate possible PAH contamination sources, specific PAH ratios were calculated. The ratios reflected a predominant petrogenic input. A characterisation of surface active substances was also performed on SML and SSW samples, both by gas bubble extraction, and by dynamic surface tension measurements. Results showed a good correlation between n-alkanes, PAHs and refractory organic matter.
\end{abstract}

(c) 2008 Elsevier B.V. All rights reserved.

\section{Introduction}

The sea surface microlayer (SML) represents the boundary layer between the ocean and the atmosphere having a typical thickness of $40-100 \mu \mathrm{m}$ [1]. The SML is considered to be a complex and unique ecosystem [1,2], which comprises a series of sub-layers [3], with their own physical, biological and chemical properties. Numerous substances accumulate at the sea surface including lipids and hydrophilic or amphiphilic organic chemicals that exhibit a particularly strong interfacial affinity. The accumulation of organic matter, especially of organic compounds with surface active properties, also causes a lowering of surface tension values [1-4]. The SML thus represents both a sink and a source for hydrophobic organic compounds, as well as a very important driver enhancing air-water exchanges via volatilisation or bubble bursting associated with breaking waves, mechanical tearing and spilling over of wave crests. Various studies have focused their attention on levels of organic and inorganic pollutants in the atmosphere, sea water, ice, snow, sediments and biota in remote areas to monitor distribution and exchange processes, but, to our knowledge, few measurements [5-7] have been made to study contamination of the SML in remote areas, such as Antarctica.

\footnotetext{
* Corresponding author.

E-mail addresses: acincinelli@unifi.it, acincinelli@hotmail.com (A. Cincinelli).
}

Surface properties of organic matter can also influence the behaviour of the SML, and, consequently, its chemical composition. Laboratory evaluations on the kinetic of film formation for extracted fulvic acids have shown different values for the diffusion coefficient (D) during the elapsed time of film formation [9]. Values obtained, both at the beginning of film formation process, and close to the equilibrium, were $D=5 \times 10^{-8} \mathrm{~cm}^{2} \mathrm{~s}^{-1}$ and $D=1 \times 10^{-10} \mathrm{~cm}^{2} \mathrm{~s}^{-1}$ to $4 \times 10^{-10} \mathrm{~cm}^{2}$ $\mathrm{s}^{-1}$, respectively. This difference points out that diffusion is the prevalent transport process during the film formation; instead near the equilibrium, molecular interactions are prevailing on the diffusion process. Hunter and Liss [3] suggested that surface film is a gelatinous matrix, with molecules supported at the interface by inter and intramolecular interactions. Some authors [10] emphasize the multicomponent character of natural surfactant films and the consequent complications in attempting to predict interfacial elastic properties due to the diverse chemical makeup of such films.

The aim of this study was to provide updated data about aliphatic (nalkanes and squalene) and aromatic hydrocarbons (PAHs) concentrations in the SML and subsurface sea water (SSW) samples from Antarctica coastal waters (Ross Sea, Antarctica) and identify possible sources and partitioning of pollutants between the dissolved and particulate fractions. In this paper we also attempt to make a correlation between the enrichment factor of fulvic acids (FA) extracted from SML and SSW samples and the pollutants here investigated. As well known from literature [8], FA play an important role in binding organic and inorganic pollutants, influencing their sea-to-air transfer. In this paper we also report 


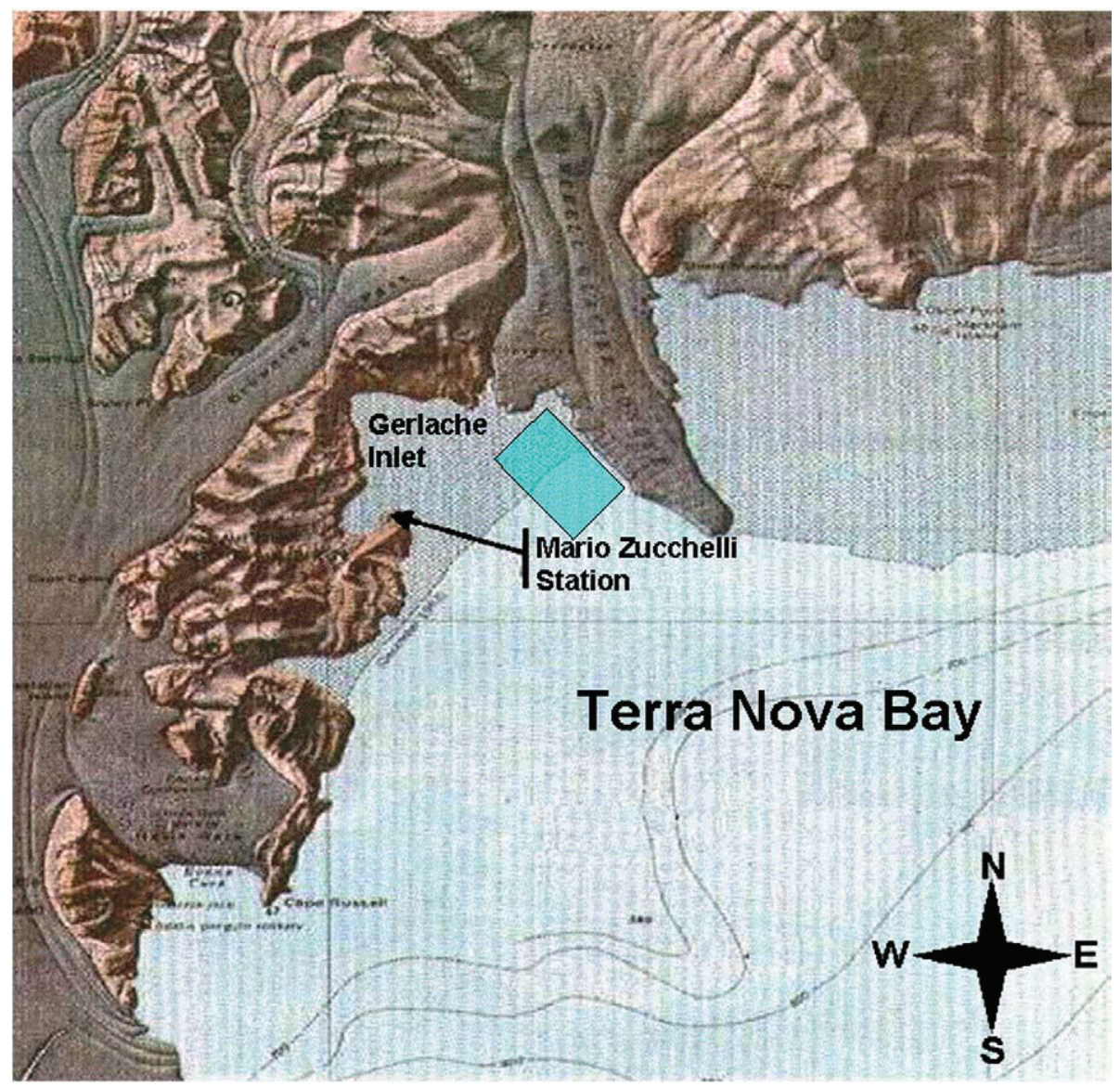

Fig. 1. Map of sampling area. The position of the Italian Antarctic base, Mario Zucchelli Station, is also shown.

some results obtained from dynamic surface tension measurements with the aim to evidence the behaviour of the SML sampled in relation to the pollutants investigated here.

\section{Experimental}

\subsection{Sample location}

During the 2000/01 Italian Antarctic Campaign sea surface microlayer (SML) and subsurface sea water (SSW) samples were collected in the Gerlache Inlet (Lat. $74^{\circ} 41^{\prime}$ S-Long. $164^{\circ} 07^{\prime} 85^{\prime \prime}$ E, Ross Sea, Antarctica, see Fig. 1). In Table 1 information about sampling conditions (sampling data, meteorological conditions and average wind speed) are shown. Samplings started few days after the pack-ice breaking.

\subsection{Sea surface microlayer sampling}

A variety of distinct methods have been used to sample the sea surface for chemical and biological analysis. Currently, the screen [11], the rotating drum [12], the glass plate [13], and Teflon plate methods are

Table 1

Summary of the performed sampling campaign.

\begin{tabular}{llll}
\hline Sample & $\begin{array}{l}\text { Date of sampling } \\
\mathrm{mm} / \mathrm{dd} / \text { yyyy }\end{array}$ & Meteorological condition & $\begin{array}{l}\text { Average wind } \\
\text { speed }\left(\mathrm{m} \mathrm{s}^{-1}\right)\end{array}$ \\
\hline SML1 and SSW1 & $02 / 03 / 2001$ & Calm-light breeze & 1.98 \\
SML2 and SSW2 & $02 / 05 / 2001$ & Calm-light breeze & 0.39 \\
SML3 and SSW3 & $02 / 07 / 2001$ & Calm-light breeze & 1.48 \\
SML4 and SSW4 & $02 / 12 / 2001$ & Variable-squalls of wind & 3.99 \\
SML5 and SSW5 & $02 / 14 / 2001$ & Calm-light breeze & 0.96 \\
\hline
\end{tabular}

SML $=$ Sea Surface Microlayer SSW = Subsurface Sea Water the most widely used [4]. The Multi-Use Microlayer Sampler (MUMS) [5-7,14-16] was used to collect SML and SSW samples simultaneously. This device consists of a radio controlled floating structure which can collect SML and SSW at the same time. The SML was collected by a combined action a rotating Pyrex glass drum and a Mylar scraper, while SSW was directly collected from surface water $(\sim-0.50 \mathrm{~m})$. In both cases, collected samples were stored separately in clean aluminium bottles using an on board double channel Teflon membrane pumps. The volume collected was of $25 \mathrm{l}$, and the time of collection usually was around 7-8 h. The depth of the sea in the sampling area was around $300 \mathrm{~m}$.

\subsection{Sample treatments and measurements}

\subsubsection{Extraction and analytical procedure}

The analytical procedure used for sea water samples is described in details elsewhere [5,14]. Briefly, particulate and dissolved fractions were separated by filtration through glass fibre filters (Whatman GF/F, $0.45 \mu \mathrm{m}$ nominal pore size) using an all glass vacuum holder. All sample matrices were spiked with a mixture of surrogate standards (heicosane-d42, heicosene, tetradecene and tryphenylbenzene) before the extraction. Dissolved organic compounds extractions were performed with n-hexane by the replicated extractant enrichment method, according to Desideri et al. [17]. Filters were treated with a mixture of ultrapure water and methanol $(4: 1 \mathrm{v} / \mathrm{v})$ in a cold ultrasonic bath (Bransonic 3200, USA) for $25 \mathrm{~min}$, then extracted in triplicate with $4 \mathrm{ml}$ of a n-hexane-methylene chloride mixture $1 / 1 \mathrm{v} / \mathrm{v}$ by magnetic stirring for $15 \mathrm{~min}$. All extracts were anhydrified with sodium sulphate and reduced to a final volume of $100 \mu \mathrm{l}$ by a gentle stream of purified nitrogen.

All extracts were cleaned-up by using Silica gel 60 HR (Merck) column $(0.6 \times 10 \mathrm{~cm})$, as described elsewhere [5,14]. n-Alkanes analysis were conducted using a Varian 4290 gas chromatograph- 
mass spectrometer (GC-MS) according to a procedure and temperature program described elsewhere [14]. Separation and identification of the investigated PAHs (fluorene (FL), phenanthrene (PHE), anthracene (ANT), fluoranthene (FLT), pyrene (PY), benzo(a)anthracene (BaA), chrysene (CHRY), benzo(b)fluoranthene $(\mathrm{BbF})$, benzo(k)fluoranthene $(\mathrm{BkF})$, benzo(a)pyrene $(\mathrm{BaP})$, dibenzo(a,h)anthracene (DBA), benzo (g,h,i)perylene (BghiP) and indeno(1,2,3-cd)pyrene (IP)) were achieved using HPLC (LC-10 AD, Shimadzu) with UV (SPD M10A VP, Shimadzu) and fluorescence detection (detector RF551, Shimadzu), as reported in Cincinelli et al. [5,14]. All concentrations were given in terms of water volume.

\subsubsection{Chemicals and materials}

All solvents and sodium sulfate used were pesticide grade. Standard PAH mixture EPA 610 was obtained from Supelco (Bellefonte, PA, USA). Tetradecene, heicosene and tryphenylbenzene were purchased from Alltech (Deerfield, USA), while heicosane-d42 was purchased from Chiron (Trondheim, Norway). Sodium sulphate was baked at $450{ }^{\circ} \mathrm{C}$ for $12 \mathrm{~h}$ to remove any organic matter and kept at $120{ }^{\circ} \mathrm{C}$ until use. All glassware and stainless steel bottles were cleaned before use by repeated washing with a hot mixture of chromic acid concentrated sulphuric acid, ultrapure water and finally dried in an oven at $130{ }^{\circ} \mathrm{C}$ for $30 \mathrm{~min}$. Glass fibre filters were baked for $12 \mathrm{~h}$ at $450{ }^{\circ} \mathrm{C}$ and wrapped in pre-cleaned aluminium foil (baked at $450{ }^{\circ} \mathrm{C}$ for $12 \mathrm{~h}$ ). Pasteur pipettes and samples vials were rinsed with acetone and dried at $220^{\circ} \mathrm{C}$ before use.

2.3.2.1. Quality assurance. Some precautions were taken to avoid contamination in the laboratory. Blanks procedure was performed as reported elsewhere $[18,19]$. The blank concentration of organic compounds were $0.8-1.3 \mathrm{ng} \mathrm{l}^{-1}$ for n-alkanes, and 0.002-0.006 $\mathrm{ng} \mathrm{l}^{-1}$ for PAHs. The concentration levels reported in Table 2 were obtained by subtracting the blanks from the values measured by chromatograms. Detection limits were quantified as the mean concentration in the field blank plus three times the standard deviation (1.8 $\mathrm{ng}^{-1}$ for n-alkanes and $0.012 \mathrm{ng} \mathrm{l}^{-1}$ for PAHs).

2.3.2.2. Gas bubble extraction. No filtered sea surface microlayer and subsurface samples have been treated according to a non-foaming gasbubble extraction procedure $[20,21]$, which essentially mimics the gas-

Table 2

Total concentraion (ng l ${ }^{-1}$ ) of n-alkanes, CPI (carbon Preference Index), squalene and PAHs in SML and SSW samples and their relative enrichment factors (EF).

\begin{tabular}{|c|c|c|c|c|c|c|}
\hline & \multicolumn{3}{|c|}{ Dissolved phase } & \multicolumn{3}{|c|}{ Particulate phase } \\
\hline & $\overline{\mathrm{SML}}$ & SSL & $\overline{E F}$ & $\overline{\mathrm{SML}}$ & SSL & $\mathrm{EF}$ \\
\hline \multicolumn{7}{|l|}{ Sample 1} \\
\hline n-Alkanes $\left(\mathrm{C}_{15}-\mathrm{C}_{32}\right)$ & 287 & 241 & 1.2 & 681 & 312 & 2.2 \\
\hline CPI & 0.59 & 0.67 & & 0.30 & 0.63 & \\
\hline Squalene & 385 & 253 & 1.5 & 425 & 265 & 1.6 \\
\hline PAHs & 4.41 & 2.40 & 1.8 & 7.82 & 4.66 & 1.7 \\
\hline \multicolumn{7}{|l|}{ Sample 2} \\
\hline n-Alkanes $\left(C_{15}-C_{32}\right)$ & 354 & 175 & 2.0 & 577 & 281 & 2.1 \\
\hline CPI & 0.46 & 0.33 & & 0.52 & 0.51 & \\
\hline Squalene & 265 & 154 & 1.7 & 328 & 179 & 1.8 \\
\hline $\mathrm{PAHs}$ & 8.11 & 2.23 & 3.6 & 15.83 & 4.20 & 3.8 \\
\hline \multicolumn{7}{|l|}{ Sample 3} \\
\hline n-Alkanes $\left(C_{15}-C_{32}\right)$ & 382 & 209 & 1.8 & 423 & 250 & 1.7 \\
\hline CPI & 0.46 & 0.67 & & 0.58 & 0.64 & \\
\hline Squalene & 319 & 205 & 1.6 & 619 & 318 & 1.9 \\
\hline PAHs & 5.60 & 2.85 & 2.0 & 6.21 & 3.45 & 1.8 \\
\hline \multicolumn{7}{|l|}{ Sample 4} \\
\hline n-Alkanes $\left(C_{15}-C_{32}\right)$ & 152 & 128 & 1.2 & 201 & 164 & 1.2 \\
\hline CPI & 0.60 & 0.34 & & 0.53 & 0.54 & \\
\hline Squalene & 112 & 130 & 0.9 & 225 & 197 & 1.1 \\
\hline PAHs & 4.25 & 2.46 & 1.7 & 3.07 & 2.81 & 1.1 \\
\hline \multicolumn{7}{|l|}{ Sample 5} \\
\hline n-Alkanes $\left(C_{15}-C_{32}\right)$ & 349 & 151 & 2.3 & 521 & 329 & 1.6 \\
\hline CPI & 0.57 & 0.38 & & 0.74 & 0.42 & \\
\hline Squalene & 263 & 138 & 1.9 & 375 & 264 & 1.4 \\
\hline PAHs & 6.02 & 2.14 & 2.8 & 9.80 & 2.88 & 3.4 \\
\hline
\end{tabular}

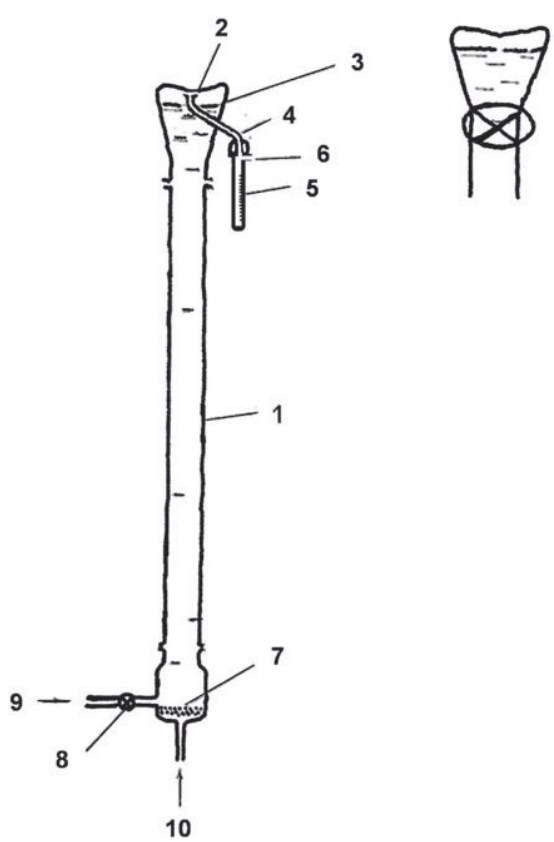

Fig. 2. Scheme of the non-foaming gas-bubble device (aerosolizzation treatment): 1) Pyrex glass column; 2) surface impact; 3) liquid level; 4) aerosol gatherer; 5) graduated measuring tube; 6) nitrogen outlet; 7) fritted glass funnel; 8) valve; 9) liquid inlet; 10) nitrogen inlet. For enrichment treatment the liquid at the column head is isolated by a tap at the end of the treatment.

bubble rising along the bulk sea water coupled with the adsorption on the bubble interface of surface active substances. This procedure was used for the extraction of surfactant material $[20,21]$.

A Pyrex glass column system with two different head set up was used. One of them enriches (E) the sample by bubbling, while the other aerosolises (A) the sample by drop ejection. In both cases, the liquid was collected in a clean bottle. Ultrapure nitrogen was used as carrier for the bubbling treatment (flux $8 \mathrm{~cm}^{3} \mathrm{~min}^{-1}$ ). A sketch of the device is reported in Fig. 2. For any treatment the device cleaning was performed without the head set up according to the following protocol: acetone, Milli_Q water, discharge and aspiration of residual liquids from the column bottom side, $\mathrm{HNO}_{3} 2 \%$ solution for $12 \mathrm{~h}$, discharge and aspiration of residual liquids from the column bottom side, Milli_Q water wash, Milli_Q water refill and bubbling and discharge from the column up side, discharge and aspiration of residual liquids from the column bottom side, closing of the column with a clean column head, and nitrogen conditioning before the refill with the sample. Column head set ups were cleaned separately using the same procedure and materials reported before.

Emission spectra fluorescence measurements for humic substances chromophores, carried out using a Perkin-Elmer LS-50B spectrofluorimeter [22-24], were performed on samples obtained by bubble procedure. Values have been normalised according to the formula $I_{\text {norm }}=I_{\max } / I_{\text {raman }} \times 100$, where: $I_{\max }$ corresponds to the maximum of fluorescence spectra of fulvic acids (FA) chromophores (range 400$450 \mathrm{~nm}$ ); $I_{\text {Raman }}$ corresponds to the maximum intensity of Raman peak water. $I_{\text {norm }}$ values are expressed in arbitrary units. Other spectra values obtained from optimisation procedure were also used, as qualitative data for the signal interpretation [22-24]. Enrichment Ratios (ERs) for enriched (E) and aerosolised (A) samples were obtained both for SML, and SSW, according to the formula:

$\mathrm{ER}_{E \text { or } A}=I_{\text {norm }}$ treated SML or SSW $/ I_{\text {norm }}$ untreated SML or SSW

Measurements of dynamic surface tension [25] were performed on untreated samples, both for SML, and SSW. The limit elastic modulus $\left(\varepsilon_{0}\right)$ were calculated according the formula:

$\varepsilon_{0}=-(\partial \gamma / \partial \ln \Gamma)$ 
where: $\varepsilon_{0}$ is the limit elastic modulus expressed in $\mathrm{m} \mathrm{N} \mathrm{m}^{-1} ; \gamma$ corresponds to the surface tension; $\Gamma$ correspond to the surface concentration.

\section{Results and discussion}

\section{1. n-Alkanes, squalene and polycyclic aromatic hydrocarbons}

The total (dissolved and particulate) n-alkane concentrations ranged between 353-968 $\mathrm{ng} \mathrm{l}^{\mathrm{l}^{-1}}$ for SML, and between 292-553 ng $\mathrm{l}^{-1}$ for SSW, as reported in Table 2. n-Alkanes, with carbon numbers ranging from $C_{15}$ to $C_{34}$, were detected in all SML and SSW samples. Inside this group a predominance of n-alkanes with carbon number from $C_{23}$ to $C_{34}$ was observed. Literature data [26] showed that sea-ice diatoms and ice-algae in the Antarctic Ocean could give a biogenic contribution to n-alkanes, since they have been found to have a large proportion of long chain $\mathrm{n}$ alkanes. Dissolved n-alkanes varied from 152 to $382 \mathrm{ng} \mathrm{l}^{-1}$ for SML and from 128 to $241 \mathrm{ng} \mathrm{l}^{-1}$ for SSW, while particulate n-alkanes ranged from 201 to681 ng $\mathrm{l}^{-1}$ for SML and from 164 to $329 \mathrm{ng} \mathrm{l}^{-1}$ for SSW (see Table 2). n-Alkanes concentrations were found lower in the dissolved phase than in the particulate adsorbed fraction both in SML and SSW samples.

Even if it is hard to compare the results from studies performed using different sampling devices, which may have collected different layer thickness [4], it could be pointed out that total n-alkanes concentrations in SML samples of the investigated Antarctic area are much lower than those reported for n-alkanes in the SML of anthropic area such as Leghorn (Italy) (1.23-3674 $\mu \mathrm{g} \mathrm{I}^{-1}$ ) [14] and Chesapeake Bay (USA) (21.2$245 \mu \mathrm{g} \mathrm{l}^{-1}$ ) [27]. The n-alkanes levels reported in this paper can be compared with those measured during a previous Italian Antarctic expedition at Terra Nova Bay [5], where dissolved n-alkanes were found to range from 223 to $532 \mathrm{ng} \mathrm{l}^{-1}$ for SML and from 108 to $298 \mathrm{ng} \mathrm{l}^{-1}$ for SSW. Instead, particulate n-alkanes ranged from 377 to $767 \mathrm{ng} \mathrm{l}^{-1}$ for SML and from 192 to $574 \mathrm{ng}^{-1}$ for SSW. Authors [5] suggested a predominantly biogenic origin for this class of organic compounds. However, lower (4.1-10.5 $\mathrm{ng} \mathrm{l}^{-1}$ ) [28] and higher (1.1-21.8 $\mu \mathrm{g} \mathrm{l}^{-1}$ ) [29] n-alkanes concentrations were observed for sea water samples collected in the area of Bransfield Strait. This variability could be probably related to either the phytoplankton production or to the contamination of the Antarctica by anthropogenic hydrocarbons due to isolated spillage incidents, research station activities and shipping, as suggested by Cripps and Priddle [30].

Aliphatic hydrocarbons are present in the lipid fraction of all marine flora and fauna and consequently this is the largest potential source in the Antarctic region, because natural input from the land to the marine system is very limited due to the sparse terrestrial biota. Thus, biogenic n-alkanes were expected to dominate the hydrocarbons at Gerlache Inlet between
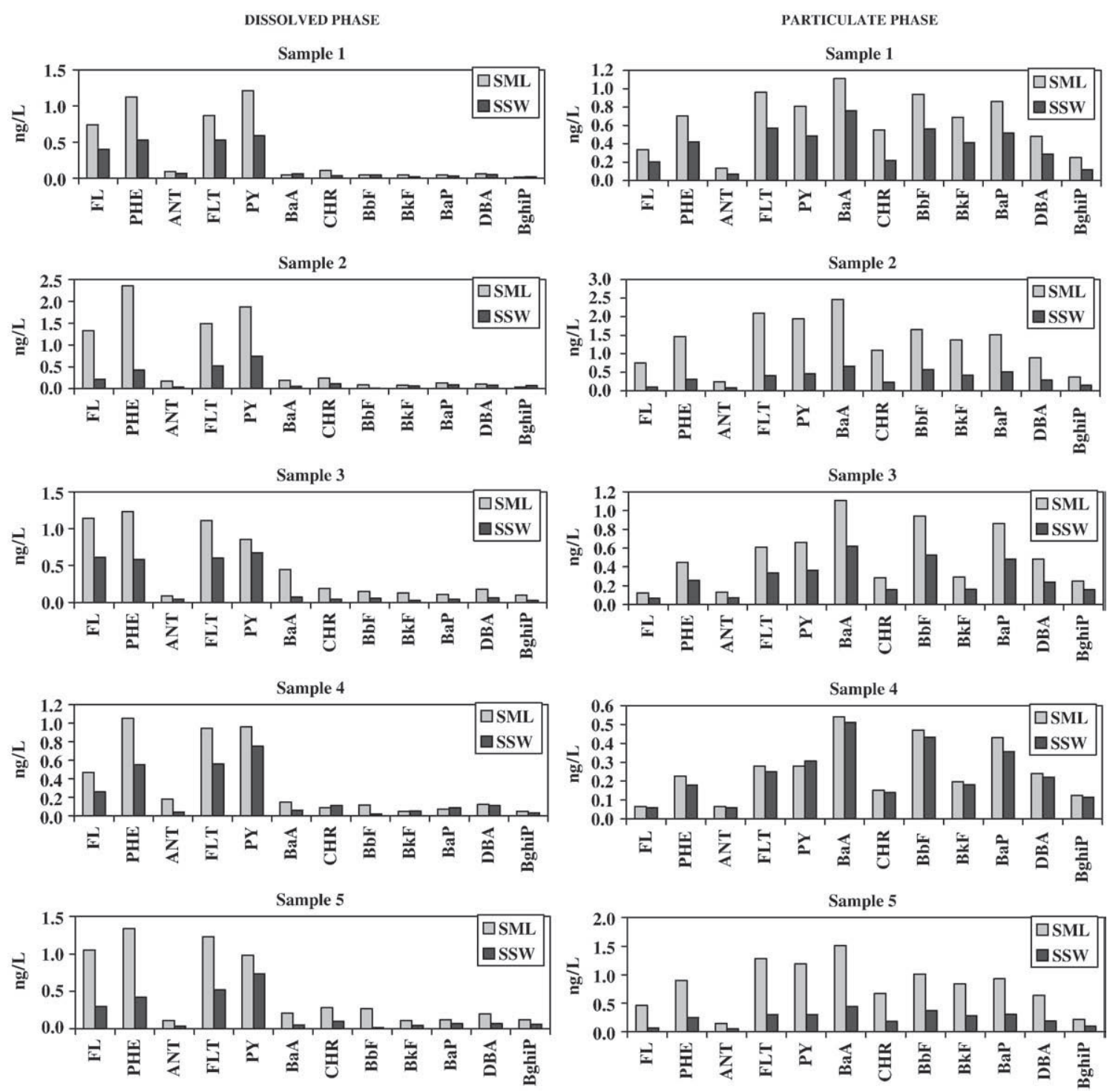

Fig. 3. PAHs distribution in dissolved phase and particulate phase. 


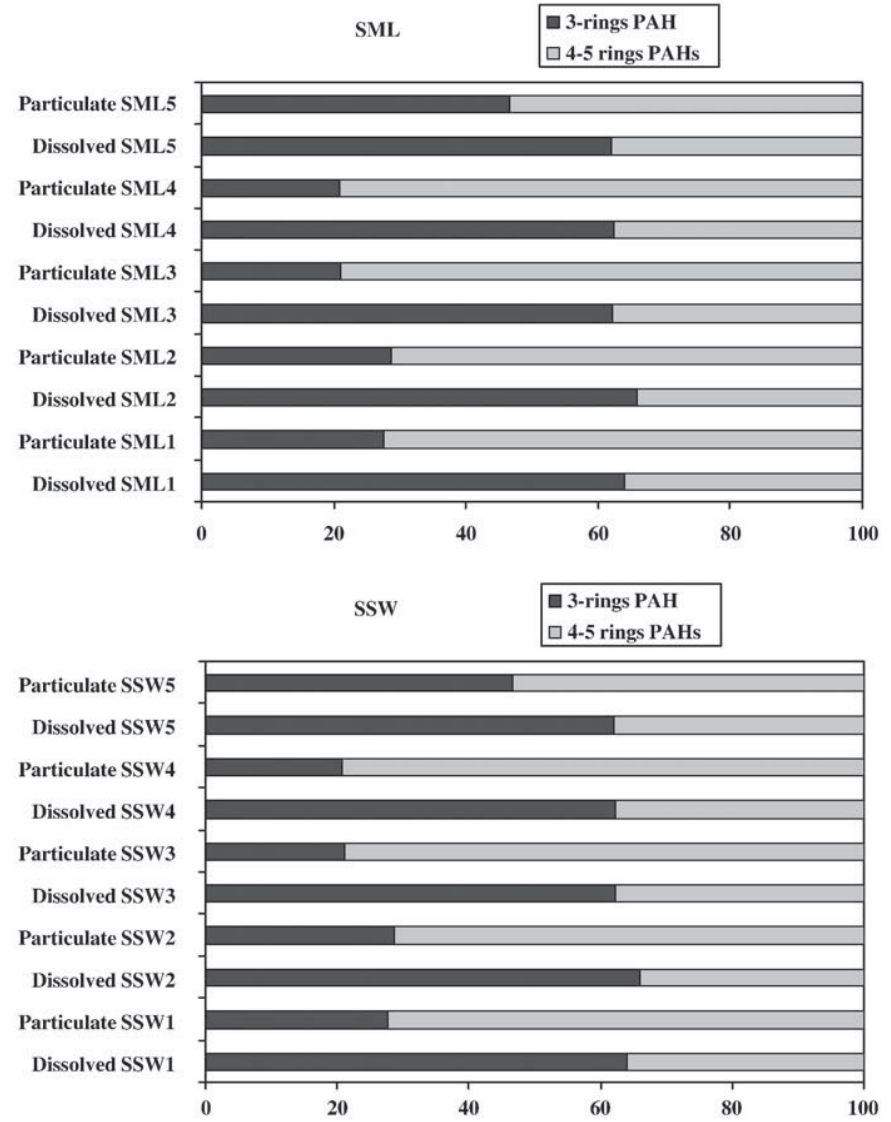

Fig. 4. Relative \% abundance of PAHs in the dissolved and particulate phases of SML and SSW samples.

January to March because it was shown to be the period of maximum phytoplankton biomass production [31-32]. Two major algal blooms alternatively dominate phytoplankton populations of the Ross Sea: diatoms and prymnesiophyceous, in particular Phaecocystis antarctica [33]. Both groups occur in spring whereas diatoms dominate summer phytoplankton assemblages. Moreover, due to an anomalous extensive ice coverage observed during the summer 2001, Mangoni et al. [34] found a three-fold increase in Chlorophyll $a$ concentrations, and consequently in phytoplankton biomass in the Ross Sea.

The Carbon Preference Index (CPI), which was calculated over the range $\mathrm{C}_{15}-\mathrm{C}_{32}$, is a parameter that has frequently been used as a source indicator of n-alkanes. According to Bray and Evans [35], CPI is the ratio of the sum of odd to the sum of even carbon numbered n-alkanes. CPI values from petroleum and anthropogenic activities are close to 1 ; whereas higher CPI values could indicate greater biogenic contribution. As reported elsewhere [36], terrestrial plants and marine algae show an odd carbon predominance, but it has already been reported that in the Antarctica region marine organisms can exhibit odd/even ratios both less and more than 1 [36]. In this study, we found CPI values always lower than 1 for both particulate and dissolved fractions. For all samples, dissolved phase showed a bimodal distribution with a maximum at $C_{16}$ and $C_{24}$, while the particulate phase was dominated by long chain compounds in the range $\mathrm{C}_{24}-\mathrm{C}_{32}$, with $\mathrm{C}_{24}$ as dominant n-alkane. These results supported the assumption of a natural origin of aliphatic hydrocarbons [5] in the coastal area of Terra Nova Bay (Antarctica).

Squalene, an acyclic $C_{30}$ isoprenoid, originating mainly from the phytil side chain of chlorophyll $a$ and found in diatom blooms [37,38], can be used as a biological marker. Significant amounts of squalene were found in the sea water samples, and the values in the dissolved phase of SML were higher than those of SSW (see Table 2), supporting the predominant natural origin of aliphatic hydrocarbon.
Polycyclic aromatic hydrocarbons (PAH) are generally considered as indicators of contamination from anthropogenic sources. Except for minor contributions from bacteria and microalgae, PAH are not known to be synthesized by organisms [39]. The presence of PAH may be attributed to both petrogenic and pyrogenic sources [40], such as long range transport through different pathways (e.g. river run off, water mass circulation and long range atmospheric transport, isolated shipwrecks, research station and/or shipping activities).

SML samples from a variety of seas and oceans show a very wide range of PAH concentrations. In general, relatively high concentrations of PAHs in the SML have been detected in marine environments, most likely due anthropogenic coastal activities such as shipping harbours. For example the total concentration of PAHs in the SML in the harbour of Los Angeles was up to $55.81 \mu \mathrm{g} \mathrm{l^{-1 }}$ [41], in Chesapeake Bay [27] up to $6 \mu \mathrm{g} \mathrm{l^{-1 }}$ and in Leghorn (Italy) up to $170 \mu \mathrm{g} \mathrm{l^{-1 }}$ [14].

The concentrations found in SML and SSW samples collected at Gerlache Inlet were extremely low and confirm the still pristine characteristics of the Antarctica environment. On one hand, dissolved phase PAH concentrations varied from 4.25 to $8.11 \mathrm{ng} \mathrm{l}^{-1}$ for SML and from 2.14 to $2.85 \mathrm{ng} \mathrm{l}^{-1}$ for SSW. On the other hand, PAH content in sea water particulate ranged from 3.07 to $15.83 \mathrm{ng} \mathrm{l}^{-1}$ in SML and from 2.81 to $4.66 \mathrm{ng} \mathrm{l}^{-1}$ in SSW. The lowest concentrations were observed for samples SML4 and SSW4, for both dissolved and particulate phases. In fact a strong wind speed was recorded during the sampling period [42]. Wind speed is the major factor, in comparison to temperature or solar irradiation, which influences both particulate and dissolved PAHs enrichments.

PAH distributions in the dissolved and particulate phases of SML and SSW samples are reported in Fig. 3. PAHs are hydrophobic compounds with very low water solubility, thus the distribution between the particulate and dissolved phases is strictly related to the octanol-water constant distribution $\left(K_{\text {ow }}\right)$ of these compounds, as reported in Fig. 4. While three ring PAHs are predominant in the dissolved phase, the heaviest PAHs are most abundant in the particulate phase.

The sources of PAHs, either from petrogenic and pyrolytic origin, may be identified by ratios of specific PAH compounds [43-46]. A ratio between low molecular weight (LMW), two or three rings, and high molecular weight (HMW), four to six rings, higher than 1, dominates in the petrogenic source $[43,44]$. Some authors $[45,46]$ also suggested that $\mathrm{PAH}$ contamination of a petrogenic origin is characterized by phenanthrene/anthracene (PHE/ANT) ratio $>10$ and fluorine/pyrene (FL/PYR)< 1 , while PHE/ANT ratio $<10$ and $\mathrm{FL} / \mathrm{PY}>1$ have been suggested for pyrolytic sources. Even if, low PAH concentrations were found in this study, this approach was applied to all dissolved and particulate samples of SML and SSW collected in the Gerlache Inlet, and results are shown in Table 3. It seems hard to assign a specific source, even if LMW/HMW ratios seem to indicate a petrogenic origin of PAHs, as suggested by Fuoco et al. [5] for SML and SSW samples collected in the same area, during the 1997/98 Italian Antarctic Expedition. The petrogenic source might be due to either natural processes or only be attributed to local sources, like micro spills and/or small leaks. It is difficult to state if the levels of PAH measured in sea water samples of Gerlache Inlet could only be attributed to these contributions, because PAHs are known to be highly resistant to degradation processes and their presence could be also due to aged air masses reaching Antarctica by long-range transport.

Table 3

LMW/HMW, PHE/ANT and FL/PY values for SML and SSL samples collected at Gerlache Inlet.

SML1 SSW1 SML2 SSW2 SML3 SSW3 SML4 SSW4 SML5 SSW5

\begin{tabular}{llllllllllll}
\hline LMW/HMW & 1.6 & 1.3 & 1.3 & 1.3 & 1.1 & 1.4 & 1.8 & 1.4 & 1.5 & 1.7 \\
PHE/ANT & 8 & 7 & 9 & 6 & 8 & 7 & 5 & 7 & 9 & 8
\end{tabular}

$\begin{array}{lllllllllll}\text { FL/PYR } & 0.5 & 0.6 & 0.5 & 0.3 & 0.8 & 0.7 & 0.4 & 0.3 & 0.7 & 0.4\end{array}$


Table 4

ER values from SML and SSW samples treated with non-foaming-gas-bubble procedure.

\begin{tabular}{|c|c|c|c|c|c|}
\hline & & \multicolumn{4}{|c|}{ Treatment } \\
\hline & & \multicolumn{2}{|c|}{ Enriched } & \multicolumn{2}{|c|}{ Aerosolised } \\
\hline & & $\overline{\text { ER-SML }}$ & ER-SSW & ER-SML & ER-SSW \\
\hline \multirow[t]{5}{*}{ Sample } & 1 & 33.66 & 2.26 & 84.03 & - \\
\hline & 2 & 21.69 & 2.98 & 30.39 & 12.60 \\
\hline & 3 & 87.47 & 4.59 & 21.28 & - \\
\hline & 4 & 1.91 & 2.70 & 11.40 & 140.71 \\
\hline & 5 & 59.54 & 2.63 & 38.46 & - \\
\hline
\end{tabular}

Enrichment factor (EF) for the microlayer relative to underlying bulk water can be calculated as the ratio of the volumetric concentration (ng $1^{-1}$ ) found in the microlayer to that of sub-surface water sample. The estimation of EFs provides a measure of the degree of enrichment of a range of lipophilic compounds including toxicants. Recently, a review paper on pollutants in the sea surface microlayer has reported [4], that the concentration data and the EF values so far published are rather contradictory. Such a high variability of enrichment factors is manly due to the thickness of the SML, that has actually been collected. The thickness of the SML may vary considerably depending on the sampling system and on a number of external factors including water temperature, the presence and density of surface slicks and, for the rotating drum based sampling system, the speed of rotation $[4,6]$. In our data, hydrocarbons are always accumulated in SML in comparison to the SSW samples.

Generally speaking, hydrocarbons are not surface active substances and should therefore be minor constituents of SML. However, previous studies $[47,48]$ have shown that both fulvic and humic acids can fix and retain hydrocarbons by incorporation into their molecular sieve-type structure. This together with their surface activity and their chelator properties have increased the attractiveness of dissolved humic materials like growth promoters for phytoplankton [49]. Consequently, these humic materials act like ligand agents, and may play a major role, which justifies the requirements for assessments hydrocarbons surface activity.

Samples collected during the 2000/01 Italian Antarctic Campaign (SML + SSW) were also analysed for humic substances by Calace et al. [7] Fulvic acids were present both in subsurface (total range: $0.2-0.3 \mathrm{ng} \mathrm{l}^{-1}$ ) and in microlayer (total range: $0.6-2.4 \mathrm{ng} \mathrm{l}^{-1}$ ) waters. The greater amount of FA in the microlayer samples could explain the hydrocarbons predominance in SML in comparison to SSW. Authors [7] also found that whereas microlayer $100 \%$ of FAs were constituted by $>3000$ Da fraction, in the subsurface only $70 \%$ of the FAs contained the same fraction.The remaining part of fulvic acid fraction in SSW (30\%) fell into the $<3000$ Da fraction [7]. It is interesting to note that according to literature data [46] a greater aliphatic nature for molecules of larger size was expected.

The lower n-alkane concentrations and enrichments found for sample 4 (see Table 2) could be due to the rough sea condition and destruction of the SML during the sample collection. In general, humic substances constitute almost $50 \%$ of the dissolved organic carbon.

Dissolved PAHs showed less enrichment in the SML than particulate PAHs. The stronger enrichment found in the particulate


Fig. 5. a and b - Raman background peak values for SML $\square$ and SSW $\square$ enriched $(E)$ and aerosolised samples $(A)$. phase for PAHs reflects their stronger tendency to be associated with particulate matter [36], which is accentuated at low temperature [50]. There is also evidence that flocculated particles floating on the surface may act as an important sink for persistent organic pollutants in the SML.

\subsection{Gas bubble extraction}

Gas-bubbles scavenge the bulk water mass for several metres while rising to the surface, and collect the surfactant matter and those components, which are able to interact with the air/water interface, before breaking. The prevalent mechanism in this process is a continue adsorption-desorption equilibrium of surface-active material on the bubble-water interface. The velocity of a single rising bubble in a surfactant solution depends on the distance covered, as well as, the time elapsed across a pathway from its release-point [5156]. When surfactant is adsorbed on the surface of a gas-bubble rising, surface-bubble is less mobile, friction increases, and consequently, rising-bubble velocity decreases [57,58].

Enrichment ratios values (ERs), obtained by fluorescence measurements on gas-bubble extracted samples, could give an idea about the surfactant fluorescent organic matter (SFOM) adsorbed on gas-bubbles $[57,58]$. In addition, wavelength band could give an idea about the quality of the extracted material. From our previous observations [24], for $\lambda_{\max }$ values near to the Raman peak ( $\lambda_{\text {Raman }} \sim 360 \mathrm{~nm}$ ), the maximum of fluorescence is generally covered by the flocculation of the extracted material. In this case, we assume that "labile material" is greater than "refractory material". In fact, for samples which $\lambda_{\max }$ values are $>400 \mathrm{~nm}$, organic substance showed a well-defined fluorescence maximum in agreement with values for fulvic acids (which are prevalent in sea water). It is known that the surface activity of humic substances is higher than fresh formed organic matter [26], and fluorescence emission values range between 400 and $450 \mathrm{~nm}$. The ER values for enriched $(E)$ and aerosolised $(A)$ samples show generally higher values for SML than for SSW, as shown in Table 4. Only sample SML4, for the enrichment treatment process, showed an opposite trend probably due to the instable meteorological conditions recorded during sampling. The wavelengths of $I_{\max }$ showed values higher than $400 \mathrm{~nm}$, for all SML samples, except for sample SML4. For SSW samples, values higher than $400 \mathrm{~nm}$ for samples SSW1 and SSW2, and values $<400 \mathrm{~nm}$ for all the others were measured. These results are in agreement with those found by Calace et al. [7] for FA extracted from the same samples.

In Fig. 5a and $b$ values of the background-Raman-peak for treated samples are reported. The background-Raman-peak value was used only as a qualitative indicator of flocculated material, and it was obtained from the normalisation of the spectra procedure [22-24].

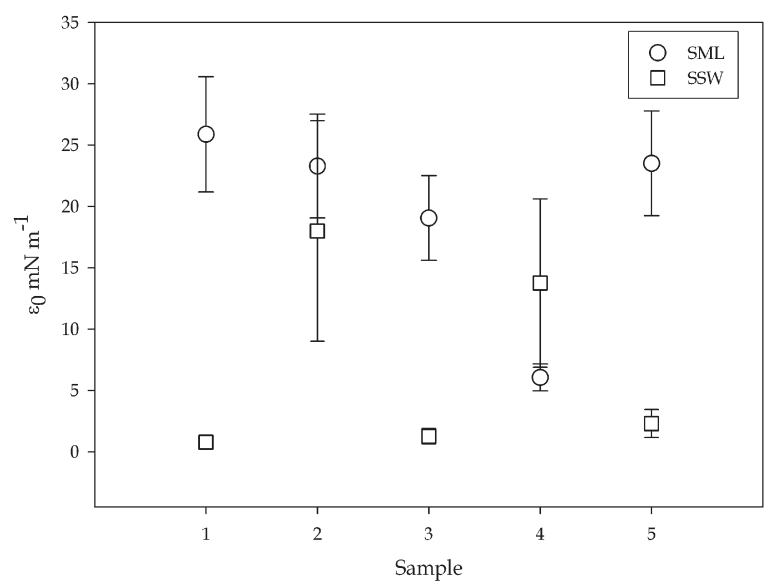

Fig. 6. Limit elastic modulus values $\left[\varepsilon_{0}=-(\mathrm{d} \gamma / \mathrm{d} \ln \Gamma)\right]$ and their respective errors for SML and SSW samples. 
Data emission spectra obtained for SML and SSW in enriched samples (E) showed a high flocculation of fluorescent organic matter, which was higher in SML samples with respect to SSW ones. Also in this case SML4 sample showed a different trend. For aerosolised samples $(A)$ (see Fig. 5b), whereas SSW values were all comparable (except for SSW1), SML values were recorded only for samples SML2 and SML4. No product from the aerosolisation treatment was obtained for SML1, SML3 and SML5 samples. In these cases, a really dense foam-layer which performed on the top surface sample during the treatment (about $1 \mathrm{~cm}$ of thickness), prevented the drop ejection of material from the column to the bottle.

Values of $\varepsilon_{0}$ obtained from dynamic surface tension measurements and their respective errors (see Fig. 6), show a decreasing trend going from SML1 to SML3 (from 25.8 to $19.1 \mathrm{mN} \mathrm{m}^{-1}$ ). As previously reported, the first part of the sampling period was characterized by calm sea conditions, while sample SML 4 was collected in rough sea conditions and its related $\varepsilon_{0}$ value is the smallest $\left(6.1 \mathrm{mN} \mathrm{m}^{-1}\right)$ of the SML sampling period. In the case of SML5 the $\varepsilon_{0}$ value obtained was $23.5 \mathrm{mN} \mathrm{m}^{-1}$ and calm sea conditions also characterized this sampling. According to the literature, the most hydrophobic surfactants are normally preferred in a competitive behaviour between different classes of surfactants in a surface film $[59,60]$. On the other hand, taking into account the meteorological conditions of Gerlache Inlet area during the sampling period of microlayer (see Table 1), and the molecular characteristics and the total amount of FA acids extracted from the same pool of samples [7], it is possible to hypothesize that the trend of $\varepsilon_{0}$ is well correlated with the surface activity of FA (refractory organic matter), which is usually higher than the fresh formed organic matter. n-Alkanes (dissolved + particulate) values trend is also well correlated with $\varepsilon_{0}$ values. The trend of $\varepsilon_{0}$ values, which is the result of the variation of surface tension in relation to the surface concentration, is also in agreement with the movement of particulate matter from the surface to the bottom of water column (typical process for the period here considered) [61], and the mixing of surface water column by rough sea condition. For SSW samples the range of $\varepsilon_{0}$ values goes from 0.7 to $18.0 \mathrm{mN} \mathrm{m}^{-1}$, and a trend was not present, either for n-alkanes, and or for FA.

\section{Acknowledgements}

We express many thanks for their helpful collaboration to: the whole staff of climantartide ${ }^{1}$ (in particular to Dr. A. Pellegrini, Dr. P. Grigione and Dr. U. Gentili) and Prof. B.M. Petronio and Dr. N. Calace (for FA data). This manuscript was funded by the Italian National Programme for Antarctic Research (Programma Nazionale di Ricerche in Antartide - PNRA).

\section{References}

[1] WHO, The sea-surface microlayer and its role in global change. IMO/FAO/UNESCOIOC/WMO/WHO/IAEA/UN/UNEP: Joint Group of Experts on the Scientific Aspects of Marine Environmental Protection (GESAMP), Reports and studies N ${ }^{\circ}$. 59, WMO, Geneva, 1995.

[2] K.A. Hunter, P.S. Liss, Mar. Chem. 5 (1977) 361-379.

[3] K.A. Hunter, P.S. Liss, Organic sea surface films. In Marine Organic Chemistry, E.K. Duursma and R. Dawson, eds., Elsevier, Amsterdam, 259-298.

[4] O. Wurl, P.J. Obbard, Mar. Pollut. Bull. 48 (2004) 1016-1030.

[5] A. Cincinelli, A.M. Stortini, L. Checchini, T. Martellini, M. Del Bubba, L. Lepri, J. Environ. Monit. 7 (2005) 1305-1312.

[6] R. Fuoco, S. Giannarelli, Y. Wei, C. Abete, S. Francesconi, M. Termine, J. Environ. Monit. 7 (2005) 1313-1319.

[7] N. Calace, S. Mirante, B.M. Petronio, M. Pietroletti, C. Rugo, Int. J. Environ. Anal. Chem. 84 (2004) 413-421.

[8] J.F. McCarthy, B.D. Jimenez, Environ. Sci. Technol. 19 (1985) 1072-1078

[9] J. Krägel, A.M. Stortini, N. Degli Innocenti, G. Loglio, R. Cini, R. Miller, Colloid Surf. A 101 (1995) 129-135.

[10] S.J. Pogorlzeski, A.D. Kogut, A.Z. Mazurek, Hydrobiologia 554 (2006) 67-81.
[11] W.D. Garrett, Limnol. Oceanogr. 10 (1965) 602-605.

[12] G.W. Harvey, Limnol. Oceanogr. 11 (1966) 608-613.

[13] G.W. Harvey, L.A. Burzell, Limnol. Oceanogr. 17 (1972) 156-157.

[14] A. Cincinelli, A.M. Stortini, M. Perugini, L. Checchini, L. Lepri, Mar. Chem. 76 (2001) $77-98$.

[15] L. Manodori, A. Gambaro, R. Piazza, S. Ferrari, A.M. Stortini, I. Moret, G. Capodaglio, Mar. Pollut. Bull. 50 (2005) 165-174.

[16] N. Calace, N. Calmieri, S. Mirante, B.M. Petronio, M. Pietroletti, Water Res. 40 (2006) 1109-1118.

[17] P.G. Desideri, L. Lepri, L. Cecchini, Mikrochim. Acta 107 (1992) 55-63.

[18] M. Del Bubba, A. Cincinelli, L. Cecchini, L. Lepri, P.G. Desideri, Int. J. Environ. Anal. Chem. 84 (anno) 441-456.

[19] A. Cincinelli, P.G. Desideri, L. Lepri, L. Cecchini, M. Del Bubba, R. Udisti, Int. J. Environ. Anal. Chem. 349 (1999) 283-299.

[20] R.M. Gershey, Limnol. Oceanogr. 17 (1983) 395-400.

[21] G. Loglio, U. Tesei, P. Cellini Legittimo, E. Ravanelli, R. Cini, Ann.Chim. (Rome) 71 (1981) 251-261.

[22] R. Cini, N. Degli Innocenti, G. Loglio, G. Orlandi, A.M. Stortini, U. Tesei, Int. J. Environ. Anal. Chem. 55 (1994) 285-295.

[23] R. Cini, B.M. Petronio, N. Degli Innocenti, A.M. Stortini, C. Braguglia, N. Calace, Ann. Chim. (Rome) 84 (1994) 425-430.

[24] N. Degli Innocenti, "Messa a punto tecnica di estrazione HS dalle acque secondo il metodo Malcolm-Thurman. Valutazione fluorescenza e reologia", PhD Thesis in Environmental Sciences at University of Pisa (1993).

[25] G. Loglio, U. Tesei, R. Cini, Rev. Sci. Instrum. 59 (1988) 2045-2050.

[26] P.D. Nichols, J.K. Volkman, A.C. Palmisano, G.A. Smith, D.C. White, J. Phycol. 24 (1988) 90-96.

[27] J.T. Hardy, E.A. Crecelius, L.D. Antrim, S.L. Kiessere, V.L. Broadhurst, P.D. Bohem, W.G Steinhauer, T.H. Coogan, Mar. Chem. 28 (1990) 333-351.

[28] J. Sanchez-Pardo, J. Rovira, Hicrocarburos alifaticos y aromaticos policiclicos detectados en aguas del Estrecho de Bransfield. Expedition BIOMASS III (Antactic'86), in CASTELL VI, Ed. Actas del Segundo Symposium Espanol de studios Antarcticos, Coseno Superior de Investigazione Cientificas, Madrid, 1987, pp. 117-124.

[29] G.C. Cripps, Mar. Pollut. Bull. 24 (1992) 109-114.

[30] G.C. Cripps, J. Priddle, Antarct. Sci. 7 (1995) 127-136.

[31] G.C. Cripps, Deep-sea Res. Part II 42 (1995) 1123-1135.

[32] W.O. Smith Jr, R.T. Barber, M.R. Hiscock, J. Marra, Deep-sea Res. Part II 47 (2000) 3119-3314.

[33] W.O. Smith Jr, L.V. Asper, Deep-sea Res. Part I 48 (2001) 137-161.

[34] O. Mangoni, M. Modigh, F. Conversano, G.C. Carrada, V. Saggiomo, Deep-Sea Res. Part I 51 (2004) 1601-1617.

[35] E.E. Bray, E.D. Evans, Geochim. Cosmochim. Acta 22 (1961) 2-15.

[36] G.C. Cripps, Polar Biol. 10 (1990) 393-402.

[37] J.F. Rontani, J.K. Volkman, Org. Geochem. 34 (2003) 1-35.

[38] T. Bieger, T.A. Abrajano, J. Hellou, Org. Geochem. 26 (1997) 207-218.

[39] A. Saliot, Natural hydrocarbons in sea water, in: E.K. Duursam, R. Dawson (Eds.), Marine organic Chemistry, Elsevier Scientific Publishing Company, Amsterdam, 1981.

[40] G. Green, J.H. Skerratt, R. Leeming, P.D. Nichols, Mar. Pollut. Bull. 25 (1992) 293-302.

[41] J.N. Cross, J.T. Hardy, J.E. Hose, G.P. Hershelamn, L.D. Antrim, R.W. Gossett, E.A. Crecelius, Mar. Environ. Res. 23 (1987) 307-323.

[42] K. Liu, R.M. Dickhut, Environ. Sci. Technol. 31 (1997) 2777-2781.

[43] S. Azimi, V. Rocher, M. Muller, R. Moilleron, D.R. Thevenot, Sci. Total. Environ. 337 (2005) 223-239.

[44] Z. Wang, M. Fingas, D.S. Page, J. Chromatogr. A843 (1999) 369-375.

[45] A. El Nemr, A.M.A. Abd-Allah, Chemosphere 52 (2003) 1711-1716.

[46] H. Budzinski, I. Jones, J. Bellocq, C. Pièrard, P. Garrigues, 58 (1997) 85-97.

[47] J.P. Mantoura Riley, Anal. Chim. Acta 76 (1975) 97-106.

[48] G. Ogner, M. Schnitzer, Geochim. Cosmochim. Acta 34 (1970) 921-928.

[49] H.S. Shin, Y.M. Monsallier, G.R. Choppin, Talanta 50 (1999) 641-647.

[50] P.A. Meyers, J.Q. Quinn, Geochim. Cosmochim. Acta 37 (1973) 1745-1759.

[51] J.V. Robinson, J. Phys. Colloid Chem. 51 (1947) 431-437.

[52] F.H. Garner, A.H.P. Skelland, Chem. Eng. Sci. 4 (1995) 149-158.

[53] M. Linton, K.L. Sutherland, Dynamic surface forces, drop circulation and liquid-liquid mass transfer, SecondInternational Congress on Surface Cativity, vol 1, Butterworth, London, 1957, pp. 495-501.

[54] N.M. Aybers, A. Tapuccu, Warme-und Stoffubertragung 2 (1969) 118-128.

[55] A.Z. Zhou, N.O. Egiebor, L.R. Plitt, Can. Metal. Q. 31 (1992) 11-16.

[56] M. Jordan, H. Sucker, A. Einsele, F. Widmer, H.M. Eppenberger, Biotechnol. Bioeng. 43 (1993) 446-454.

[57] Y. Zhang, J.B. McLaughlin, J.A. Finch, Chem. Eng. Bioeng. 56 (2001) 6605-6616

[58] C. Oppo, S. Bellandi, N. Degli Innocenti, A.M. Stortini, G. Loglio, E. Schiavuta, R. Cini, Mar. Chem. 63 (1999) 235-253.

[59] W.D. Garrett, U.S. Naval Research Laboratory, 1964, pp. 1-14.

[60] A.M. Stortini, R. Cini, R. Traversi, R. Udisti, in: M. Colacino, G. Giovannelli (Eds.), Conference proceedings about, "Italian Research on Antarctic Atmosphere", vol. 69, SIF, Bologna, 2000, p. $411-420$.

[61] S. Dalla Riva, M.L. Abelmoschi, E. Magi, F. Soggia, Chemosphere 56 (2004) 59-69. 